\title{
Mortality from dementia among gastroduodenal ulcer patients
}

Trond P Flaten, Eystein Glattre, Asgaut Viste, Odd Søreide

\begin{abstract}
Study objective-The aim was to examine whether a high intake of aluminium containing antacids is a risk for Alzheimer's disease.

Design-The mortality from dementia (1970-87), coded from death certificates as underlying or contributory cause of death, was compared with national rates in a cohort of patients who had surgery for gastroduodenal ulcer disease between 1911 and 1978.
\end{abstract}

Setting-Patient data were obtained from patient records from major hospitals in western Norway.

Participants -4179 patients were identified who met the study criteria, which included having had a documented stomach operation, having a reliably identifiable personal number, and being alive on Jan 1, 1970.

Measurements and main results-The standardised mortality ratio for dementia was $1.10(95 \%$ CI $0.85-1 \cdot 40, n=64)$ for all patients, while for patients operated on in the period 1967-78 it was 1.25 (95\% CI 0.662.13, $n=13$ ).

Conclusions-As the majority of patients operated on after 1963 have probably been heavy consumers of aluminium containing antacids, the study provides meager evidence that a high intake of aluminium is an important risk factor for Alzheimer's disease, the major cause of dementia. However, the possibility of a raised mortality from Alzheimer's disease cannot be ruled out due to probable misclassification both in diagnosis and exposure. In addition, the observation period may have been too short to detect an effect since the latent period for Alzheimer's disease may be very long.

Evidence suggests that aluminium is associated with Alzheimer's disease, ${ }^{1-3}$ but whether it is involved in the aetiology or pathogenesis of the disease, or is concentrated secondarily in neuropathological lesions as an effect of the disease, remains an open question. ${ }^{4}$ The average dietary intake of aluminium is less than $10 \mathrm{mg}$ per day in most European countries, ${ }^{5-8}$ whereas the intake is probably somewhat higher in the USA due to more widespread use of aluminium containing food additives. ${ }^{910}$ In contrast, people who regularly take aluminium containing antacids may ingest more than one gram of aluminium per day. ${ }^{9}$ Most peptic ulcer patients have been heavy and regular consumers of antacids, especially before the introduction of $\mathrm{H}_{2}$ blockers in the late 1970s. Accumulation of aluminium in bone has been reported in a peptic ulcer patient with normal renal function with a 25 year history of high oral aluminium ingestion. ${ }^{11}$

The purpose of the present work was to investigate mortality from dementia in a cohort of 4179 patients who had surgery for gastroduodenal ulcer disease between 1911 and $1978 .{ }^{12}$ Alzheimer's disease is the most common cause of dementia, ${ }^{13} 14$ and most patients in the cohort will probably have used aluminium containing antacids.

\section{Methods}

In a previous study, ${ }^{12}$ we reported an increased risk of stomach cancer in patients having had surgery for gastroduodenal ulcer disease. This cohort of 4179 patients is characterised by (a) there having been a documented stomach operation (resection or gastroenterostomy, but not vagotomy) in the past; (b) the patient was alive on January 1, 1970; (c) a stomach cancer had not been diagnosed prior to 1970; (d) the patient's person number (an 11 digit number unique to each Norwegian individual alive in 1960 and born thereafter) could be reliably identified. The patient data were obtained from official operation protocols for the period 1900-78 and histopathological reports on resected stomach specimens examined during the period 1944-78. The patients were operated on in the period 1911-78; only $0.9 \%$ were operated on before 1930 , and $5.0 \%$ before 1940 . Other relevant information has been given by Viste et al. ${ }^{12}$

In Norway, all deaths must be reported to the Central Bureau of Statistics. Here, up to three causes other than the underlying cause of death are coded from the information recorded on the death certificate. In the following, these other causes are referred to as "contributory causes". Based on the person numbers, the patient data file was matched against the death register file. Of 1953 deaths between January 1, 1970 and December $31,1987,7^{\circ}$ o were coded with four causes of death, $15 \%$ with three causes, $37^{\circ}{ }_{0}$ with two causes, and $41 \%$ with one cause; 1734 deaths were coded according to ICD-8 (1970-85), and 219 according to ICD-9 (1986-87).

Deaths coded with ICD codes 290.0 and 290.1 (senile and presenile dementia), either as underlying $(n=12)$ or contributory $(n=51)$ cause of death, and with ICD 9331.0 (Alzheimer's disease; $\mathrm{n}=1$, contributory cause) were included. No deaths were coded with ICD 9 290.2-290.9. Standardised mortality ratios (SMR) were 
calculated using the national age and sex specific mortality rates for 11 age groups $(45-49, \ldots$, $85-89$ and $90+$ years) in the period $1974-83^{15}$ to estimate the expected numbers of deaths. As dementia mortality stayed fairly constant in Norway from 1969 to $1983,{ }^{15}$ we considered it acceptable to use the mean annual rates for 1974-83 to represent the period under study (1970-87). The numbers of person-years were calculated for the individual patients as the difference between the year of death (or 1987 for the 2226 patients still alive; these patients were assigned an extra 0.5 person-year) and the year of operation. The person-years were grouped in the 11 age groups according to the year of birth. For seven patients $(0.17 \%)$ who had emigrated after 1970 , the number of person-years was calculated as the difference between the year of emigration and the year of operation. Confidence intervals (CI) for the SMRs were calculated assuming a Poisson distribution.

\section{Results}

The total observed (and expected) number of deaths in the different age groups were: $<60$ years: $0(0 \cdot 3), 60-64: 1(0 \cdot 6), 65-69: 1(2 \cdot 6), 70-74$ : 5 (7.0), 75-79: 14 (13.1), 80-84: 18 (16.6), 85-89: $19(12 \cdot 1), 90+: 6(5 \cdot 8)$, total: $64(58 \cdot 2)$. The largest difference is found in the 85-89 year group, where the SMR is $1.56(95 \%$ CI $0.94-2 \cdot 45)$.
Table I Standardised mortality ratio's (SMR) for dementia (1970-87) coded as the underlying or a contributory cause of death in a cohort of 4179 patients who had surgery for gastroduodenal ulcer disease in the period 1911-78

\begin{tabular}{|c|c|c|c|c|}
\hline $\begin{array}{l}\text { Year of } \\
\text { operation }\end{array}$ & $\begin{array}{l}\text { No of } \\
\text { cases }\end{array}$ & $A g e^{\mathrm{a}}$ & $S M R$ & $95 \% C I$ \\
\hline $\begin{array}{l}1911-78 \\
1911-49 \\
1950-58 \\
1959-66 \\
1967-78\end{array}$ & $\begin{array}{r}44 \\
8 \\
15 \\
11 \\
10\end{array}$ & $\begin{array}{l}\text { Men } \\
81 \cdot 8 \\
83 \cdot 1 \\
82 \cdot 4 \\
80 \cdot 5 \\
81 \cdot 1\end{array}$ & $\begin{array}{l}1.15 \\
0.58 \\
1.56 \\
1.34 \\
1.52\end{array}$ & $\begin{array}{l}0.84-1.55 \\
0.26-1.15 \\
0.87-2.57 \\
0.67-2.40 \\
0.73-2.79\end{array}$ \\
\hline $\begin{array}{l}1911-78 \\
1911-49 \\
1950-58 \\
1959-66 \\
1967-78\end{array}$ & $\begin{array}{r}20 \\
6 \\
3 \\
8 \\
3\end{array}$ & $\begin{array}{l}\text { Women } \\
83 \cdot 7 \\
84.3 \\
85 \cdot 3 \\
85 \cdot 9 \\
74.7\end{array}$ & $\begin{array}{l}0.99 \\
1.16 \\
0.59 \\
1.31 \\
0.79\end{array}$ & $\begin{array}{l}0 \cdot 61-1 \cdot 54 \\
0 \cdot 43-2 \cdot 54 \\
0 \cdot 12-1.74 \\
0 \cdot 57-2.59 \\
0 \cdot 16-2.31\end{array}$ \\
\hline $\begin{array}{l}1911-78 \\
1911-49 \\
1950-58 \\
1959-66 \\
1967-78\end{array}$ & $\begin{array}{l}64 \\
14 \\
18 \\
19 \\
13\end{array}$ & $\begin{array}{l}\text { Both sexes } \\
82 \cdot 3 \\
83 \cdot 6 \\
82 \cdot 9 \\
82 \cdot 7 \\
79 \cdot 6\end{array}$ & $\begin{array}{l}1.10 \\
0.74 \\
1.23 \\
1.33 \\
1.25\end{array}$ & $\begin{array}{l}0.85-1.40 \\
0.41-1.25 \\
0.73-1.94 \\
0.80-2.08 \\
0.66-2.13\end{array}$ \\
\hline
\end{tabular}

$\mathrm{CI}=$ Confidence interval

Table II Frequencies of causes of death (1970-87, underlying cause of death only) among 4179 patients who had surgery for gastroduodenal ulcer disease in the period 1911-78, and among the total Norwegian population over 30 years of age

\begin{tabular}{|c|c|c|c|c|c|c|c|}
\hline \multirow[b]{2}{*}{ Disease group (ICD 8) } & & \multicolumn{3}{|l|}{ Men } & \multicolumn{3}{|c|}{ Women } \\
\hline & & $\overline{n^{\mathrm{a}}}$ & $\% \mathrm{~b}$ & Norway $^{c}$ & $n^{\mathrm{a}}$ & $\%^{b}$ & Norway $^{\mathrm{c}}$ \\
\hline $\begin{array}{l}\text { Infectious/parasitic } \\
\text { Malignant neoplasms } \\
\text { Endocrine etc } \\
\text { Mental disorders } \\
\text { Nervous/sense organs } \\
\text { Circulatory system } \\
\text { Ischaemic heart disease } \\
\text { Cerebrovascular disease } \\
\text { Respiratory system } \\
\text { Digestive system } \\
\text { Genitourinary system } \\
\text { Musculoskeletal etc } \\
\text { Symptoms/Ill defined } \\
\text { Violent deaths }\end{array}$ & $\begin{array}{l}(000-136) \\
(140-209) \\
(240-279) \\
(290-315) \\
(320-358) \\
(390-458) \\
(410-414) \\
(430-438) \\
(460-519) \\
(520-577) \\
(580-629) \\
(710-738) \\
(780-796) \\
(E 800-999)\end{array}$ & $\begin{array}{r}17 \\
442 \\
14 \\
21 \\
20 \\
670 \\
425 \\
143 \\
141 \\
54 \\
24 \\
7 \\
61\end{array}$ & $\begin{array}{r}1 \cdot 1 \\
27 \cdot 8 \\
0 \cdot 9 \\
1 \cdot 3 \\
1 \cdot 3 \\
42 \cdot 1 \\
26 \cdot 7 \\
9 \cdot 0 \\
8 \cdot 9 \\
3 \cdot 4 \\
1.5 \\
0 \cdot 4 \\
3 \cdot 8 \\
6 \cdot 4\end{array}$ & $\begin{array}{r}0.6 \\
21 \cdot 1 \\
0.9 \\
0 \cdot 7 \\
1 \cdot 2 \\
51 \cdot 6 \\
31 \cdot 2 \\
11 \cdot 6 \\
8.5 \\
2.5 \\
1 \cdot 6 \\
0 \cdot 3 \\
4 \cdot 5 \\
5 \cdot 4\end{array}$ & $\begin{array}{r}4 \\
67 \\
7 \\
10 \\
4 \\
148 \\
52 \\
57 \\
48 \\
19 \\
10 \\
4 \\
17 \\
21\end{array}$ & $\begin{array}{r}1 \cdot 1 \\
18 \cdot 5 \\
1.9 \\
2 \cdot 8 \\
1 \cdot 1 \\
40 \cdot 9 \\
14 \cdot 3 \\
15 \cdot 7 \\
13 \cdot 2 \\
5 \cdot 2 \\
2 \cdot 8 \\
1 \cdot 1 \\
4 \cdot 7 \\
5 \cdot 8\end{array}$ & $\begin{array}{r}0.7 \\
20 \cdot 9 \\
1 \cdot 3 \\
0 \cdot 8 \\
1 \cdot 2 \\
51 \cdot 2 \\
22 \cdot 3 \\
17 \cdot 2 \\
9.9 \\
2.9 \\
1.4 \\
0 \cdot 7 \\
3 \cdot 8 \\
4 \cdot 3\end{array}$ \\
\hline
\end{tabular}

a The numbers of disease specific deaths in the cohort

b The numbers of disease specific deaths in the cohort as percentages of the total numbers (1590 men, 363 women)

$c$ The numbers of disease specific deaths in Norway as percentages of the total numbers of deaths among persons over 30 years
As the most important aluminium based antacids were registered for sale in Norway around 1963, the cohort was split, according to year of operation, into four groups containing approximately equal numbers of deaths. No SMR is significantly different from 1 (table I), and no clear time trend is observed. To explore trends in SMRS related to the year of operation, the values were calculated for 16 overlapping operation time periods, representing progressively more recent operations (figure).

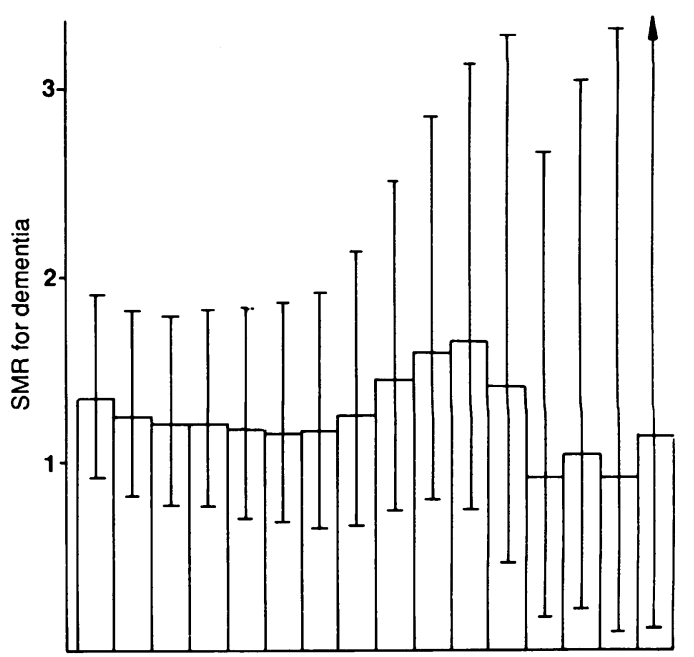

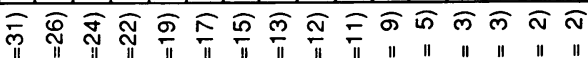

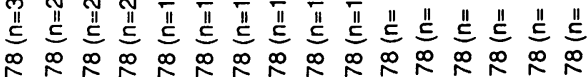

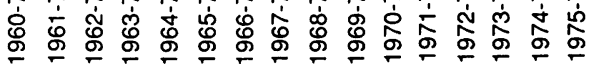

Year of operation

Standardised mortality ratios (SMR) for dementia (1970-87) coded as the underlying or a contributory cause of death for patients who had surgery for gastroduodenal ulcer disease in the time periods indicated. The bars indicate $95 \%$ confidence intervals.

Among the patients operated on in the period 1967-78, the SMR for those operated on after the age of 70 (seven dementia cases) was $1.50(95 \% \mathrm{CI}$ 0.60-3.09); for those operated on before the age of 70 (six cases), the SMR was 1.04 (95\% CI 0.382.28).

For all deaths coded with dementia in Norway in the period 1974-83 the mean age at death was 81.7 years for men $(n=5642)$ and 83.5 for women $(n=9085)$. In the cohort, the corresponding numbers were 81.8 years for men and 83.7 for women (table I).

We compared the frequencies of causes of death in the present cohort with those in the general population (table II). The mean age at death in the cohort was 71.9 years for men and 77.7 for women, while the mean expectation of life in Norway in the period $1971-85$ was $72 \cdot 1$ years for men and 78.6 for women. Although the spectrum of causes of death in the cohort was not very much different from that in the general population, some divergence existed: the frequency of cardiovascular deaths, especially from ischaemic heart disease, was lower among the ulcer patients. This could possibly be due to a selection bias: people with heart problems may not be as eligible for surgery as people without. Thirty seven percent of the excess cancer mortality among men 
was caused by stomach cancer, and $28 \%$ by lung cancer; the excess mortality from stomach cancer is probably related to surgery, as earlier demonstrated for this cohort, ${ }^{12}$ and the percentage of smokers is likely to be high among ulcer patients, explaining the extra lung cancer deaths. Smoking could also explain the extra respiratory deaths among women, $61 \%$ of which was attributed to chronic bronchitis and $36 \%$ to bronchopneumonia. Nearly all the excess mortality from mental disorders among women was caused by dementia, and that in men by alcoholism. Nearly all the excess mortality from diseases of the digestive system was caused by peptic ulcer disease.

\section{Discussion}

An association between aluminium in drinking water and dementia has been reported in Norway ${ }^{16-18}$ and in Great Britain specifically for Alzheimer's disease. ${ }^{19} \mathrm{~A}$ problem in the interpretation of these studies is that drinking water represents a minor fraction of ingested aluminium. An intake of one gram of aluminium (a typical daily dose for antacid users) necessitates an intake of several thousand litres of water, even at the highest aluminium concentrations found in Norwegian drinking water $(0.3-0.5 \mathrm{mg}$ aluminium per litre ${ }^{17}$ ).

Antacid intake has been examined in three case-control studies of Alzheimer's disease, but the number of subjects reporting past use of antacids was small, 20 or the results were inconclusive. ${ }^{22}$ Furthermore, the amount and regularity of past antacid use is difficult to assess in Alzheimer's disease patients. Colin-Jones et $a l^{23}$ analysed death certificates in a large cohort of cimetidine users, and reported only one death due to Alzheimer's disease. However, British death certificate data do not seem to be very useful in examining dementia epidemiology. ${ }^{24}$ In Norway, multiple coding of causes of death has been carried out since 1956; dementia is coded from as much as $3-4 \%$ of the total number of death certificates, ${ }^{15}$ nearly 10 times more commonly than in the USA. ${ }^{25}$ We regard Norwegian mortality data on dementia to be more complete, and hence more useful for epidemiological studies, than in most other countries. ${ }^{15}$ Even so, it is clear that the registration of dementia on death certificates is far from complete. The crucial question is whether the frequency of demented people reported on the certificates in our cohort is different from that in Norway as a whole. We see no a priori reason to assume that such differences should be large. However, continuity of care by the same doctor makes it more likely that a deterioration in mental state is recognised, and therefore that the existence of dementia is noted on the death certificate. This may be one reason for the slightly elevated SMRS in the three most recent patient groups (table I). Alcohol intake may be higher among ulcer patients than in the general population, so some cases of alcoholic dementia may have been included among our cases.

Nearly every peptic ulcer patient, especially before the introduction of cimetidine in Norway in August 1978, ${ }^{26}$ will have taken some kind of antacids. The major brands of aluminium containing antacids (mixed aluminiummagnesium preparations) were registered for sale in Norway in 1963. Before this, sodium bicarbonate and calcium carbonate were the dominating compounds in antacids. However, the antacid and ulcer therapeutic effects of aluminium hydroxide were indicated before $1940,{ }^{27} 28$ so aluminium compounds may have been taken by some patients before 1963 . Of the total sales of antacids in Norway in the 1980s, aluminium containing antacids constituted $45 \%$, measured in defined daily doses. ${ }^{29}$ Since the early 1960 s physicians in Norway have generally recommended aluminium containing antacids to ulcer patients as they have a longer duration of action than the other types, and some patients will probably also have taken more than one antacid type. Conservatively it seems reasonable to assume that from about 1963-65, more than half of the individuals with dyspepsia will have taken aluminium containing antacids. Since some patients operated on for peptic ulcer have recurrences $^{30}$ and others have dyspeptic problems, a considerable proportion of the patients in the cohort will probably also have taken aluminium containing antacids after the operation. This may explain the slightly raised SMRs in the patient groups operated on in 1950-58 and 1959-66 (table I). The low SMR for the period 1911-49 is, however, difficult to explain.

The facts that not all patients will have taken aluminium containing antacids, and that the group of cases is "diluted" with non-Alzheimer dementias, reduce the study's power to detect a small aluminium effect. However, neuropathological studies ${ }^{13} 14$ indicate that Alzheimer's disease accounts for $50-60 \%$ of the total number of dementia cases, and some additional $10-15 \%$ have the disease in combination with multi-infarct dementia.

It is possible that an established diagnosis of dementia disqualifies patients for operation for non-bleeding and non-penetrating peptic ulcers; this could bias the SMR estimates downwards. It should also be noted that the control population (Norway's total population) is also exposed to aluminium, although much less than the average ulcer patient.

Elevated SMRs for dementia could of course be due to diseases other than Alzheimer's disease, notably multi-infarct dementia. However, we see no a priori reasons to suspect an increased occurrence of multi-infarct dementia among peptic ulcer patients. Furthermore, since multiinfarct dementia in most cases arises from emboli or atherosclerosis in cerebral arteries, it is closely related to cerebrovascular disease, the mortality of which is lower in our cohort than in the Norwegian population (table II).

If an environmental agent should be involved in the aetiology of Alzheimer's disease the latent period could (but need not) be very long. It might be that the present study was unable to detect an effect of aluminium on the mortality of dementia because the time interval between the introduction of aluminium containing antacids (1963) and the time of death (1970-87) is too short. This time interval does not only cover the latent period, but also the period from onset of 
disease to death. For the 13 dementia cases operated on in the period 1967-78, the mean interval from 1963 to operation was $7 \cdot 2$ years (range 4-14), from operation to death 8.3 years (range 4-15), and from 1963 to death 15.5 years (range 12-22).

Simple consideration of total elemental intake of aluminium is possibly not very relevant in clarifying the relationship between aluminium and Alzheimer's disease. Some individuals may be vulnerable, eg, through defects in metabolism of transferrin, ${ }^{31}$ the protein carrying the bulk of aluminium in plasma. The chemistry of aluminium in biological systems is very complex,,$^{32} 33$ so its neurotoxicity may totally depend on its chemical form, or on the concomitant intake of ligands such as maltol ${ }^{34} 35$ or citrate. Citrate enhances the gastrointestinal uptake of aluminium, ${ }^{3637}$ possibly through the opening of cellular tight junctions in the proximal bowel. ${ }^{38}$ If aluminium plays an active role in the aetiology or pathogenesis of Alzheimer's disease, and should this role depend on factors outlined above, it may be very difficult indeed to demonstrate or quantitate in epidemiological studies.

In conclusion, although it should be noted that the SMRs in the three most recently operated patient groups are all slightly raised (table I, compare with the figure), the present study provides little evidence that a high intake of aluminium through antacids is a risk factor for Alzheimer's disease. On the other hand, the observation period may have been too short, and there is substantial misclassification in our diagnosis and exposure data. Therefore, we cannot rule out the possibility that the mortality from Alzheimer's disease among the regular long term consumers of aluminium containing antacids in our cohort could be considerably raised.

Note added in proof-Broe et al (Neurology 1990; 40: 1698-707) have found no association between antacid use and Alzheimer's disease in the most powerful case-control study conducted to date. Thus the cumulative results from casecontrol studies ${ }^{2-22}$ give little evidence that antacids are a strong risk factor for Alzheimer's disease.

1 Ganrot PO. Metabolism and possible health effects of aluminium. Environ Health Perspect 1986; 65: 363-441.

2 Bertholf RL. Aluminum and Alzheimer's disease: perspectives for a cytoskeletal mechanism. Crit Rev Clin perspectives for a cytoskele

3 McLachlan DRC, Lukiw WJ, Kruck TPA. New evidence for an active role of aluminum in Alzheimer's disease. Can $\mathcal{F}$ for an active role of aluminum

4 Wisniewski HM, Sturman JA. Neurotoxicity of aluminum. In: Gitelmad HJ, ed. Aluminum and health. A critical review. New York: Marcel Dekker, 1989: 125-6.

5 Koivistoinen $P$, ed. Mineral element composition of Finnish foods: N, K, Ca, Mg, P, S, Fe, Cu, Mn, Zn, Mo, Co, Ni, Cr, $\mathrm{F}, \mathrm{Se}, \mathrm{Si}, \mathrm{Rb}, \mathrm{Al}, \mathrm{B}, \mathrm{Br}, \mathrm{Hg}, \mathrm{As}, \mathrm{Cd}, \mathrm{Pb}$ and $\mathrm{Ash}$. Acto Agricult Scand / Suppl / 1980; 22: 1-171.

$6 \mathrm{Knutti}$ R, Zimmerli B. Untersuchung von tagesrationen aus schweizerischen verplegungsbetrieben. III. Blei, cadmium, quecksilber, nickel und aluminium. Mitt Gebiete Lebensmittel Hyg 1985; 76: 206-32.

7 Treier S, Kluthe $\mathrm{R}$. Aluminiumgehalte in lebensmitteln. Ernährungs-Umschau 1988; 35: 307-12.
8 Sherlock JC. Aluminium in foods and the diet. In: Massey R, Taylor D, eds. Aluminium in food and the enviroment. Cambridge: Royal Society of Chemistry Special Publication No 73, 1989: 68-76.

9 Lione A. Aluminum toxicology and the aluminumcontaining medications. Pharmacol Ther 1985; 29: 255-85.

10 Pennington JAT: Aluminium content of foods and diets. Food Addit Contam 1988; 5: 161-232.

11 Recker RR, Blotcky AJ, Leffler JA, Rack EP. Evidence for aluminum absorption from the gastrointestinal tract and bone deposition by aluminum carbonate ingestion with normal renal function. F Lab Clin Med 1977; 90: 810-5.

12 Viste A, Opheim P, Thunold J, et al. Risk of carcinoma following gastric operations for benign disease. Lancet 1986; ii: 502-5.

13 Tomlinson BE, Blessed G, Roth M. Observations on the brains of demented old people. $\mathcal{F}$ Neurol Sci 1970; 11: 205-42. 14 Katzman R. Alzheimer's disease. N Engl f Med 1986; 314:

15 Flaten TP. Mortality from dementia in Norway, 1969-83. $f$ Epidemiol Community Health 1989; 43: 285-9.

16 Vogt $T$. Water quality and health-study of a possible relation between aluminium in drinking water and dementia (English abstract). Oslo: Central Bureau of Statistics of Norway, abstract). Oslo: Central Bureau of Statistics
1986. (Sosiale og økonomiske studier No 61.)

17 Flaten TP. An investigation of the chemical composition of Norwegian drinking water and its possible relationships with the epidemiology of some diseases. Trondheim, Norway: University of Trondheim, 1986. PhD Thesis.

18 Flaten TP. Geographical associations between aluminium in drinking water and death rates with dementia (including Alzheimer's disease), Parkinson's disease and amyotrophic lateral sclerosis in Norway. Environ Geochem Health 1990; 12: $152-67$.

19 Martyn CN, Osmond C, Edwardson JA, Barker DJP, Harris EC, Lacey RF. Geographical relation between Alzheimer's disease and aluminium in drinking water. Lancet 1989; i: $59-62$.

20 Heyman A, Wilkinson WE, Stafford JA, Helms MJ, Sigmon AH, Weinberg T. Alzheimer's disease: a study of epidemiological aspects. Ann Neurol 1984; 15: 335-41.

21 Amaducci LA, Fratiglioni L, Rocca WA, et al. Risk factors for clinically diagnosed Alzheimer's disease: a case-control for clinically diagnosed Alzheimer's disease: a case-control 22 Grudy of an Italian population. Neurology 1986; 36: 922-31. Larson EB. The association between aluminum-containing products and Alzheimer's disease. $\mathcal{f}$ Clin Epidemiol 1990; 43: 35-44.

23 Colin-Jones D, Langman MJS, Lawson DH, Vessey MP. Alzheimer's disease in antacid users. Lancet 1989; i: 1453.

24 Martyn CN, Pippard EC. Usefulness of mortality data in determining the geography and time trends of dementia. $\mathcal{F}$ Epidemiol Community Health 1988; 42: 134-7.

25 Chandra V, Bharucha NE, Schoenberg BS. Patterns of mortality from types of dementia in the United States, 1971 and 1973-1978. Neurology 1986; 36: 204-8.

26 Berstad A. Antacids and anti-ulcer drugs. In: Drug utilization in Norway during the 1970's-increases, inequalities, innovations. Oslo: Norwegian Medicinal Depot, 1983: 37-51.

27 Chrohn BB. The clinical use of a colloidal aluminum hydroxide hydroxide as a gastric antacid. $\mathcal{f}$ Lab Clin Men 1929; 14: 610 .

28 Einsel IH, Adams WL, Myers VC. Aluminum hydroxide in the treatment of peptic ulcer. Am $\mathcal{F}$ Dig Dis Nutr 1934; 1 : 513.

29 Øydvin K, ed. Legemiddelforbruket i Norge 1984-1988 (In Norwegian). Oslo: The Norwegian Medicinal Depot, 1989: 18-22.

30 Sheaff CM, Nyhus LM. Recurrent ulcer. In: Nyhus LM, Wastell C, eds. Surgery of the stomach and duodenum, 4 th ed. Boston: Little, Brown, 1986: 515-34.

31 Farrar G, Altmann P, Welch S, et al. Defective galliumtransferrin binding in Alzheimer disease and Down syndrome: possible mechanism for accumulation of aluminium in brain. Lancet 1990; 335: 747-50.

32 Martin RB. The chemistry of aluminum as related to biology and medicine. Clin Chem 1986; 32: 1797-806.

33 Birchall JD, Chappell JS. Aluminium, chemical physiology, and Alzeimer's disease. Lancet 1988; ii: 1008-10.

34 Kruck TPA, McLachlan DRC. Aluminum as a pathogenic factor in senile dementia of the Alzheimer type: ion specific factor in senile dementia of the Alzheimer type: ion specific
chelation. In: Iqbal K, Wisniewski HM, Winblad B, eds. chelation. In: Iqbal K, Wisniewski HM, Winblad B, eds. Alzheimer's disease and

35 Bertholf RL, Herman MM, Savory J, et al. A long-term intravenous model of aluminum maltol toxicity in rabbits: tissue distribution, hepatic, renal and neuronal cytoskeletal changes associated with systemic exposure. Toxicol Appl Pharmacol 1989; 98: 58-74.

36 Slanina P, Frech W, Ekström L-G, Lööf L, Slorach S, Cedergren A. Dietary citric acid enhances absorption of aluminum in antacids. Clin Chem 1986; 32: 539-41.

37 Weberg R, Berstad A. Gastrointestinal absorption of aluminium from single doses of aluminium containing antacids in man. Eur $\mathcal{f}$ Clin Invest 1986; 16: 428-32.

38 Froment DPH, Molitoris BA, Buddington B, Miller N, Alfrey AC. Site and mechanism of enhanced gastrointestinal absorption of aluminum by citrate. Kidney Int 1989; 36: 978-84. 